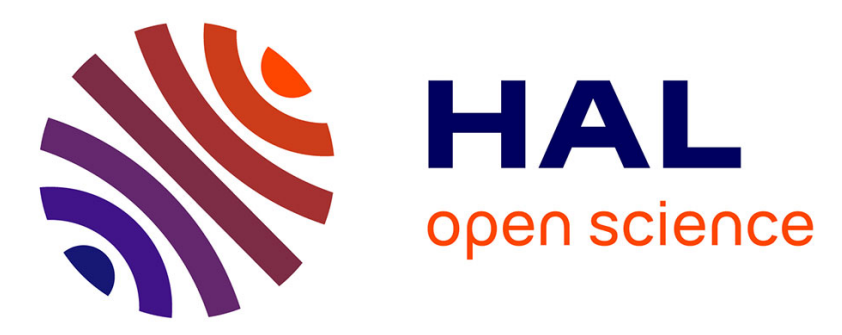

\title{
Inter-Organizational Collective Learning: The case of biotechnology in France
}

Alvaro Piña-Stranger, Emmanuel Lazega

\section{To cite this version:}

Alvaro Piña-Stranger, Emmanuel Lazega. Inter-Organizational Collective Learning: The case of biotechnology in France. European Journal of International Management, 2010, 4 (6), pp.602 - 620. hal-01800230

\section{HAL Id: hal-01800230 \\ https://hal-sciencespo.archives-ouvertes.fr/hal-01800230}

Submitted on 25 May 2018

HAL is a multi-disciplinary open access archive for the deposit and dissemination of scientific research documents, whether they are published or not. The documents may come from teaching and research institutions in France or abroad, or from public or private research centers.
L'archive ouverte pluridisciplinaire HAL, est destinée au dépôt et à la diffusion de documents scientifiques de niveau recherche, publiés ou non, émanant des établissements d'enseignement et de recherche français ou étrangers, des laboratoires publics ou privés. 


\title{
Inter-organizational collective learning:
}

The case of biotechnology in France

\author{
Alvaro Pina-Stranger \\ ORIO-IRISSO, University of Paris - Dauphine \\ alvaropinastranger@gmail.com \\ and \\ Emmanuel Lazega \\ ORIO-IRISSO, University of Paris - Dauphine \\ emmanuel.lazega@dauphine.fr
}

July 9, 2009

Forthcoming in the European Journal of Information Management Special issue edited by Miha Skerlavaj and Robert Kase 


\title{
Inter-organizational collective learning: \\ The case of biotechnology in France
}

\begin{abstract}
:
We explore inter-organizational collective learning by assuming that authority relationships are different at the inter- from the intra-organizational level. This difference has implications for the way in which a collective solves the problems related to the creation of a hierarchy between different bodies of appropriate knowledge. At the intra-organizational level, cognitive conflicts are solved by centralization and alignment with opinion leaders who often have formal and epistemic authority. In this context, members tend not to seek advice from others « below » them in the organizational status hierarchy. At the inter-organizational level, we show that the absence of a formal hierarchy encourages entrepreneurs to invest heavily in relational activity. This behavior allows them to keep their status in a context where epistemic conflicts become entrenched, following a polarization process, in different epistemic communities. We illustrate this phenomenon with an empirical study of entrepreneurs in the French biotech industry.
\end{abstract}

Key words: Cooperation - Homophily - Biotechnology industry - Collective learning Inter-organizational networks - Advice networks - Epistemic alignment - Polarization 


\section{Inter-organizational collective learning: \\ The case of biotechnology in France}

\section{Introduction}

Collective learning is considered a crucial process for the survival and performance of organizations (see for example Argyris and Schön, 1978; Argote et al., 2005 ; March and Simon, 1958; Levitt and March, 1988; Huber, 1991; Kogut and Zander, 1996; Weick 1979). Especially in knowledge intensive industries, understanding how knowledge grows, changes and is exchanged is a major issue for public authorities in charge of promoting industrial innovation. Developments in network analyses have helped observe and analyze these processes. The first studies of collective learning focused mainly on intra-organizational interactions and relations. Blau's $(1955,1964)$ seminal theoretical work shows that actors have an incentive to share their knowledge when they obtain, in exchange, recognition of their cognitive authority. By looking at advice ties, this work has identified status games and the process of epistemic alignment as central to members' capacity to learn together. The emergence of an informal pecking order, often strongly correlated with formal hierarchy, helps the collective with evaluation and control of knowledge appropriate for task performance (Škerlavaj and Dimovski, 2006).

More recently, a large body of literature has focused on construction and transfer of knowledge at the inter-organizational level, especially in new sectors of industrial innovation. Based on a relational approach to knowledge, this work examines the inter-organizational context within which innovative projects emerge, so as to study the market and non market mechanisms of scientific valuation., Several authors have studied the effect in the biotech industry of inter-organizational collaborations on the capacity of firms to grow, innovate and learn (Powell et al., 1996, Senker et Sharp, 1997, Baum et al., 2000, Salman et Saives, 2005). They focused on forms of exchange between these firms. Kogut's (2000) theoretical synthesis suggests that inter-organizational ties tend to stabilize a dominant rule of exchange: the absence of formal authority is compensated by the emergence of communities that selfregulate and allow for cooperation among its members. It is important, however, to remember that competition between different rules is not just about modalities of exchange, but also about objectives, values and identities that define the role of a collective in a wider interorganizational system which is politically constrained. The symbolic dimension of exchanges represented by these realities also contributes to the structuration of an industry. 
Taking these « non strictly economic » dimensions seriously is one of the challenges taken up by neo-structural approaches (Lazega et Mounier, 2002). These require the observation of social relations between actors at the inter-individual level. In the biotech industry, economists and geographers have shown that various physical and institutional environments (universities, technological clusters, trade associations, etc.) help scientific entrepreneurs exchange with one another (Audretsch et Stephan, 1996, Lemarié et al., 2001, Powell et al., 2002, Stuart et Sorenson, 2003, Autant-Bernard et al., 2006). These relationships represent a complex system of informal exchanges and interdependencies. The study of these interdependencies brings individuals back at the heart of explanations of inter-organizational learning.

In this paper, we explore inter-organizational learning by looking at advice ties between individual actors at the inter-organizational level. We assume that the nature of authority relationships between these actors is different at the intra- and inter-organizational levels because there is no formal hierarchy in the latter context. This difference has implications on the way a collective solves cognitive conflicts linked to the order of priorities among authorities and to appropriate bodies of knowledge. We first outline a theoretical frame that differentiates between intra- from inter-organizational interdependencies, as well as the implications of these differences for collective learning. From this theory, we then derive three hypotheses concerning this process at the inter-organizational level. We present an empirical network study among French biotech entrepreneurs and test our hypotheses based on this dataset. Finally, we discuss and outline the limitations of our approach.

\section{Formal regulation deficit and polarisation in inter-organizational collective learning}

The analysis of advice ties at the inter-organizational level can be useful for the study of the relationship between social structure of an industry and the behavior of entrepreneurs trying to appropriate and evaluate the knowledge they need.

In the study of the learning process and collective knowledge creation, a strong body of literature has focused on advice ties in professional environments (Barley, 1990, Borgatti and Cross, 2003, Cross et al., 2001, Gibbons, 2004, Hansen, 2002, Ibarra and Andrews, 2003, Kilduff and Tsaï, 2003, Krackhardt, 1987, 1990, Lazega and Van Duijn, 1997, Lazega et al. (2006a), McDonald and Westphal, 2003, Mizruchi and Stearns, 2001, Rulke and 
Galaskiewicz, 2000, Sparrowe et al., 2001, Tsaï, 2002). This is mainly due to the fact that these types of social interactions combine two different dimensions of social exchanges: an economic and a symbolic dimension. Actors sought out for advice control information, but they also have epistemic status. The first dimension refers to resources exchanged in a collective; the second to personal commitments, identities and values that allow members to politicize and contextualize their exchanges. Taking into account the two dimensions requires a theory of the judgments passed by actors to evaluate the knowledge taken into account to perform tasks. These judgments are based on technical criteria of relevance, but also on social criteria of appropriateness (Lazega, 1992). Appropriateness judgments orientate behavior because they help actors to create a hierarchy among individuals or between groups who are attributed the authority to know. Actors align themselves epistemically on authorities and, in exchange for this alignment, hope to be recognized as members of this community in which this knowledge is validated by these authorities. Out of the aggregation and articulation of these different relational choices a structure emerges, in which the epistemic communities of this collective can be identified. In simpler terms, members often conform and say what their social and power context demands of them for membership.

Status games guiding the collective evaluation and selection of appropriate knowledge are only possible in a system of functional, contractual, epistemic or hierarchical interdependencies. These interdependencies create both opportunities and constraints for actors making decisions. At the intra-organizational level, these functional and hierarchical interdependencies are often well defined because division of work is often relatively clear: : interdependencies that bring together managers, technicians, secretaries and workers can usually be described largely from the formal constraints that come attached to their tasks. Many studies have shown that, at this level, advice networks often coincides with the formal structure of the organization: actors with high epistemic status also have hierarchical authority (Lazega et al., 2006b). Firstly, authority relationships imposed by the formal structure of the organization push for conformity with respect to judgments made by hierarchical superiors. Secondly, maintenance of this epistemic domination prevents opinion leaders from seeking advice "below them" in the hierarchy or in the pecking order (Lazega and Van Duijn, 1997).

At the inter-organizational level, work on collective learning often focuses on contractual interdependencies between companies. In the biotech industry, many researchers have looked at the position of companies in the inter-organizational collaboration network. Among the main results of this research we can mention the importance of the number and 
diversity of collaborations for the growth of these firms (Powell et al., 1999); the positive impact of collaborations with academic research centres on their capacity to innovate (Baum et al., 2000, Autant-Bernard et al., 2006, Stuart et al., 2007) ; and the strong effect of geographical proximity of various kind of collaborators on the propensity to create new enterprises (Powell et al., 2002, Boufaden et al., 2005, Gertler, 2005, Aharonson et al., 2008, Gilding, 2008). These results have allowed researchers to describe the economic and, to some extent institutional, structure of this industry.

Kogut (2000) suggests that in spite of the absence of a formal authority, interorganizational ties create a dominant rule for exchanges in the industry. This means that other, competing rules did not gain sufficient support. The study of the relationships maintained by the individuals involved in the regulatory process helps look at the social conditions promoting one form of exchange as compared to another. As shown by work on the biotech industry, personalized exchange of ideas across organizational boundaries is vital for companies (Pisano, 1991, Casper, 2007, Niosi, 2003, Mangematin et al., 2003, Powell et al., 1996). The scope of $R \& D$ activities, rapid changes in health regulations, as well as the tacit dimension of knowledge used by companies create a very uncertain environment. This encourages entrepreneurs to communicate with, and seek advice from, rival peers. Selection of advisors is not trivial; it is the outcome of the evaluation made by actors of the economic and symbolic stakes involved in the negotiation of the rules and bodies of knowledge claimed by different epistemic communities.

Contrary to intra-organizational ties, the selection of advisors at the interorganizational level is not immediately determined by a formal hierarchy. The frame of these interactions is different since authority relationships are not based on hierarchical interdependencies. What happens then, with respect to coordination of exchanges, when behavior of actors is not determined by a formal hierarchical order? How are epistemic interdependencies structured at the inter-organizational level? How does the collective solve cognitive conflicts related to the evaluation of appropriate knowledge and the definition of legitimate rules?

Studies of advice ties at the intra-organizational level have shown that cognitive conflicts are solved by epistemic alignment and a movement of centralization around members with formal authority. Alignment of the many with positions of a limited number of opinion leaders helps the latter manage the learning process by imposing consensus and exercising a high cognitive control over the collective (Lazega et al. 2006b). However, at the 
inter-organizational level, the absence of a formal hierarchy weakens to some extent the epistemic authority of central actors. In that respect, we are focusing on a more "collegiate" than "bureaucratic" system since, in principle, all actors may participate in the regulatory process (Reynaud, 1989, Lazega, 2001), and particularly in the negotiations of the terms of their exchanges.

Social relationships maintained by entrepreneurs in an industry are characterized by this collegiality in exchanges ${ }^{1}$. Therefore, collective learning does not take place as it does at the intra-organizational level. At the inter-organizational level, instead of a set of judgments imposed by a subset of actors with hierarchical authority, exchange norms and appropriate knowledge are constantly negotiated by actors. This environment may polarize the collective around subsets of opinion leaders. Contrary to what happens as the intra-organizational level, the legitimacy of these opinion leaders is challenged continually. The absence of a formal hierarchy in the inter-organizational relationships should thus be at the root of weak forms of cognitive status of members with the authority to know. Social control imposed by the milieu on opinion leaders themselves requires from the latter higher relational investments. This relational hyper-activity helps them to consolidate their position because it constitutes a form of status sharing with less central actors who, in turn, have a greater interest in supporting the knowledge claims made by these opinion leaders. At the inter-organizational level, opinion leaders need to work harder to keep their informal status and influence.

In the biotech industry, the different sectors of activity (academic research, bigpharma, investors, State agencies, etc.) must negotiate the conditions under which they will try to transform scientific knowledge into therapeutic innovation. These negotiations are characterized by strong controversies between entrepreneurs who base their claims on "scientific" knowledge and entrepreneurs who base their claims on "economic" knowledge (for a detailed description of this controversy, see Pina-Stranger, 2009). During these negotiations, actors recognise each other as belonging to the same community based on identity criteria (observable through various forms of positive homophily), on a community of interests, and on cognitive status related to the different industrial sectors involved. Thus, contrary to the intra-organizational level where homophilous choices allow actors to manage constraints imposed by formal status hierarchy, at the inter-organizational level homophilous choices help with the emergence of different epistemic communities struggling to improve the relative status of their members by promoting specific bodies of knowledge and rules of exchanges. Strong relational investments by opinion leaders can be explained in part by this 
polarization movement because controversies cannot be managed using hierarchical authority arguments.

In summary, the observation of interpersonal relationships, in which actors exchange advice and confirm their commitments, helps study the ways in which the collective solves its cognitive conflicts. The choice of an advisor is based on the satisfaction of technical criteria as well as social appropriateness criteria. Both orientate the choice and ranking of legitimate epistemic authorities (and of the knowledge claims that they make), as well as the construction of professional identities and epistemic communities. At the intra-organizational level, various studies have shown that functional interdependencies often closely determine epistemic interdependencies. At that level, advice networks are characterized by a process of centralization around a core of actors who usually have formal authority, and by rules that usually discourage actors from seeking advice "below" them in the formal hierarchy or related pecking order of the organization. At the inter-organizational level, authority relationships are not determined by formal hierarchy. In this context homophily effects that characterize advice networks create polarization which reflects the plurality of sectors that try to influence the course of activities in this industry. Coexistence of different epistemic communities in a single milieu weakens the position of opinion leaders who must invest in very strong relational activity in order to maintain their status.

\section{Hypotheses}

Based on this theoretical discussion, we formulate three hypotheses about the structure and characteristics of the advice network at the inter-organizational level.

Firstly, absence of formal hierarchy and polarization weaken the cognitive status of actors with the authority to know. At the intra-organizational level, where such norms of status are protected by the formal structure of the organization, correlation between indegree and outdegree centralities is strongly negative. At the inter-organizational level this support from formal hierarchy does not exist. We predict that members' behavior seeking to compensate for this deficit will translate into a stronger propensity to seek advice, in particular for popular members with cognitive status, and thus into a positive correlation. Translated in structural terms, this can be formulated in the following hypothesis: 
Hypothesis 1: Correlation between indegree centrality scores and outdegree centrality scores in the inter-organizational advice network is positive. The stronger an actor's indegree, the stronger his/her outdegree.

As outlined above, the non hierarchical nature of authority relationships at the interorganizational level and the heterogeneity of the sectors in which entrepreneurs belong should create a movement of epistemic polarization in the collective. Our second hypothesis is thus that the analysis of advice ties and attributes of actors should identify different cohesive subgroups with few inter-group ties. Endogenous and exogenous identity criteria represented by these attributes should have a positive homophilous effect on the selection of advisors. This can be formulated as follows:

Hypothesis 2: Actors sharing the same attributes seek advice from each other more than from actors with different attributes.

Finally, our third hypothesis is related to the nature of the sub-structures characterizing the advice network. As theorised above, learning at the inter-organizational level should take place in a polarized network. This network should also be polycentric, i.e. characterized by many opinion leaders who can be sorted in the polarized system. Translated into structural terms, this can be formulated in the following hypothesis:

Hypothesis 3: Both transitive and hierarchical sub-structures coexist in the advice network.

\section{Method}

In order to test these hypotheses, we examine the effect of exogenous and endogenous attributes on advice seeking and giving behavior, we use the so-called p2 and ERGM (Siena) ${ }^{2}$ statistical models. These models deal with the interdependencies of observations characterizing network data. The p2 model (Lazega et Van Duijn, 1997, Van Duijn et al., 2004, Zijlstra et Van Duijn, 2008) works at the dyadic level. One of its main strengths is its 
capacity to deal with choices sent and choices received as interdependent. Actor's attributes and dyadic attributes can be included in the model as explanatory variables. We use this model to test for dissimilarity effects in the selection of advisors at the inter-organizational level. To do this, categorical attributes of actors were used to generate dyadic covariates which are represented in a matrix. In this matrix, 1 indicates that both actors belong respectively to the two different categories examined, and 0 otherwise.

ERGM models (Snijders et al., 2006, Robins et al. 2007, Snijders et al., 2007) identify prespecified sub-structures characterizing the network mainly at the dyadic and triadic levels, and use a stochastic approach taking into account unobserved heterogeneity in the data so as to explain the emergence of these substructures. Based on simulations, a statistical parameter is associated with each sub-structure; it is interpreted as the extent to which this substructure is important in the generation of the network as it was empirically observed. Convergence of computations towards stable parameters signals the capacity of the model to adjust to the observed data. Both endogenous (reflecting path dependency in the network) and exogenous effects (reflecting attribute-based similarities) are represented in the specified models.

\section{Dataset}

Our site is a sub-population of firms in the biotech industry in France. Data on which basis we test our hypotheses were collected from representatives of these firms using face to face interviews during the 2007-2008 academic year. Firstly, ethnographic fieldwork allowed us to carry out qualitative interviews of various kinds of actors (CEOs, CFOs, scientists, venture capitalists, consultants, etc.) and to observe numerous meetings. This helped in identifying 96 biotech companies involved in R\&D in the «human health» sector (a sub-sector of the overall biotech industry). These firms share at least three characteristics: a) they all work in the life-sciences domain; b) they represent total financial investments above $500 \mathrm{~K} €$; c) they are French founded and owned companies. Depending on its level of development, we included between one and four managers of these companies in our dataset, according to the following criteria: a) founders; b) president/director general (CEO); c) scientific director (CSO), financial director (CFO) and director of operations (COO). We then created and tested a questionnaire aimed at collecting information about their respective trajectories and ties to the other entrepreneurs. The next phase in the research was devoted to the collection of 
network data for 138 entrepreneurs. We kept 164 entrepreneurs in our final population, representing 88 companies. Information about the 26 actors who did not respond to the questionnaire was collected in public databases (except for relational choices).

\subsection{Dependent variable}

Our dependent variable is the existence of advice ties among these biotech entrepreneurs. We identified three types of activities that these companies carry out with their business partners: academic research centres, investors, and pharmaceutical companies. Our entrepreneurs must manage these three partners from the beginning to the end of the life of the company. These companies often emerge initially from academic research centres, the latter being the former employers of the scientific founders and often co-owner of patents. Investors provide entrepreneurs with funds helping the latter to develop their scientific project in a private company. They become co-owner of the company and often have a seat in the board. Finally, pharmaceutical companies are the main clients of biotech companies. They buy products in development and sign collaboration contracts with them. These three types of collaborators have shaped the industry (Arora and Gambardella, 1990, Pisano, 1991). We asked the biotech entrepreneurs to disclose the names of those advisors concerned with how to manage these partners (research centres, big-pharma companies, venture capitalists). We were able to reconstitute, for each type of partner, an advice network for the exchange of resources related to this partner. The advice network examined here is aggregates responses across the three types of resources, exclusively between organizations. This means that we did not take into account (i.e. include in the network analyzed here) intra-organizational advice ties.

\subsection{Independent variables}

We included in our analyses five attributes representing different identity criteria (Figure 1). The first two refer to the trajectory of the entrepreneurs: initial training, whether scientific (133 actors) or economic (31 actors). In the second variable ('professional origin'), entrepreneurs are categorized based on the sector in which they worked prior to working in a biotech company: biopharmaceutical industry ( 84 actors), research centre (50 actors), and finance (30 actors). 
The next three attributes concern current status of the entrepreneurs. The third variable sorts them according to current formal status in the company: a majority ( 88 actors) is CEO and is by definition present in all companies. Financial directors (CFOs) (20 actors), Scientific directors (CSO) (23 actors) and Operations director (COO) (33 actors) were hired once the company had reached a certain level of growth. The fourth variable indicates the kind of cognitive resource for which the actor was mostly sought out (informal status): 'scientific' status, where we count entrepreneurs who were sought out to help manage ties to research centres (44 actors); 'generalist' status, in which we count those who were chosen indifferently for advice about each kind of partner (scientific, financial, pharmaceutical) (43 actors); 'economic' status, for those mainly chosen to advise about managing investors (61 actors); and "pharmaceutics" in which we count those who were chosen to advise about managing pharmaceutical firms. Finally, our last variable is localisation on one of the 13 regions in France; this variable helps control for geographical proximity.

\section{- Figure 1 about here -}

\section{Results}

We used this dataset to test our hypotheses on the structure and functioning of collective learning at the inter-organizational level.

\subsection{Relational behavior of the elites at the inter-organisational level}

Our first hypothesis predicted a positive correlation between indegree and outdegree centralities in the advice networks at the inter-organisational level. Figure 2 visualizes this correlation.

\section{— Figure 2 about here -}

In the left hand figure we represent the correlation between outdegree centrality scores and indegree centrality scores for all entrepreneurs who responded to the sociometric 
questionnaire (138 actors). On the one hand, we observe that the choices of advisors tend to focus on a small number of highly central members; on the other hand, actors with strong cognitive status (highly sought out in the advice network) are also very active advice seekers. In the right hand figure, we represent the correlation between outdegree centrality scores and indegree centrality scores, but this time without the 13 main opinion leaders. The correlation remains positive, although less important in the second case.

This trend confirms our first hypothesis. Relational behavior in this advice network at the inter-organizational level is characterized by a strong relational investment. Contrary to what is observed at the intra-organizational level, the level of an actor activity in the network is correlated to his or her indegree centrality. This is particularly the case for opinion leaders who are defined as the most central leaders in terms of indegrees. Sharing status as a relational strategy with other actors less recognized in the milieu seems to allow entrepreneurs to improve their own position in the exchange network.

\subsection{A complex process of polarization in the industry}

Our second hypothesis predicted that actors sharing the same attributes would tend to seek advice from each other more than from colleagues with different attributes. In order to test this hypothesis we carried out two types of analyses. The first concerns the relationships between actors with different attributes; the second the relationships between actors with the same attributes. Our first analysis looks at dissimilarities with respect to the role in the company, professional origin, and cognitive status (as defined above) on the selection of advisors. p2 models 1 to 3 in Figure 3 report the effects of these dissimilarities on the probability of an advice tie.

\section{— Figure 3 about here -}

In these three models, negative and significant values indicate that two actors who are dissimilar tend not to seek advice from one another. Thus identity criteria represented by these attributes split the collective in several subgroups between which ties are unlikely. Notice that in each model we find negative and significant values concerning the opposition between science and the economy (i.e. between CFOs and CSOs, between financial origin and 
academic origin, and between economic status and scientific status). Model 4 examines the four variables together, controlling for each other. Parameters are all negative, indicating that each of the three identity criteria provides a specific contribution to the polarization of the network.

The second analysis examines the effect of shared attributes on the selection of advisors using ERGMs presented in Figure 4. This model includes endogenous structural effects related to substructures characterizing the network, endogenous effects related to their position in the exchange system, and exogenous effects related to actors' attributes.

\section{- Figure 4 about here -}

Parameters for similarities measure the probability that actors sharing the same attribute will seek advice from each other. The values for these parameter in Model 1 shows that having the same 'professional origin' and the same kind of 'cognitive status' increases the probability of advice seeking from one another. In Model 2, we included a dummy variable to control for the missing data (choices by the 26 persons who were not available for interview). This slightly modifies the model but the effects go in the same direction and initial training becomes significant. Finally geographical proximity does have an effect on seeking advice from one another; but the strong geographical constraint that it expresses does not weaken the effect of other attributes.

These results confirm our second hypothesis: relational choices in the advice networks at the inter-organizational level are homophilous and based on identity criteria represented by these attributes. Polarization in the learning process is based both on relational distance between dissimilar actors and on epistemic alignment within each pole. This phenomenon is complex since it cannot be reduced to the effect of one single identity criterion. Professional origin, initial training, and cognitive status all explain this polarisation.

\subsection{Structural conditions of polarization}

The five first variables in the ERGM model (Figure 4) represent structural effects characterizing path dependency in the network. They help us test the third hypothesis predicting significant and positive effects for transitive substructures. Reciprocity is strong, 
significant and positive, indicating an important tendency to seek advice from one's advisee. The second effect concerns 'alternating $k$-triangles', which is precisely the transitivity effect that we are testing ('advisors of my advisors are my advisors'). This effect, as associated with a negative effect for 'alternating independent 2-paths', indicates that advice ties tend to combine in cohesive subgroups (Snijders et al., 2006). The 'alternating out-k-stars' is also positive, high and significant. It represents the distribution of choices sent out and confirms the strong probability of transitive sub-structures (Robins and Pattison, 2005). Unlike 'alternating $k$-triangles', it signals a certain level of segmentation in the network (Robins et al., 2007), thus confirming the trend indicated by 'alternating independent 2-paths'. Finally, the negative and significant value for the '3-cycles' effect indicates that generalized exchange in this advice network (as in most advice networks observed to this day) is highly unlikely, i.e. the advisors of my advisors will avoid seeking advice from me. This is due to the strong hierarchical nature of advice networks. These results confirm our third hypothesis. Transitivity, which is a strong condition for the emergence of a polarized system, is strong in this advice network.

\section{Discussion and conclusion}

In this paper, we explore the relational structure reflecting the process of collective learning at the inter-organizational level. We started with the idea that authority relationships at that level are different from that at the intra-organizational level. This has implications for collective problem solving and for the creation of a hierarchy of cognitive authorities and bodies of knowledge. Previous research has shown that, at the intra-organizational level selection of cognitive authorities and appropriate bodies of knowledge tend to reinforce the formal organisational hierarchy. This work has shown that actors with formal authority avoid seeking advice from members « below » them in the organizational status hierarchy. This rule is however mitigated by homophilous tendencies that also orientate the choice of advisors. At the inter-organizational level, however, epistemic interdependencies are not determined by formal hierarchy. Our hypotheses have allowed us to explore the effect of this difference on inter-organisational learning.

Our results show that highly-central advisors in this inter-organizational network are among the most active advice seekers in the system. We suggest that, in contexts in which 
there is no formal hierarchy opinion leaders have to make heavy relational investments in order to maintain their position. We suggest that if these leaders choose as advisors members who are less central than they are themselves it is because this strategy, which consists in sharing status, allows them to obtain support for their knowledge claims and appropriateness criteria.

Our results also show that the 'collegiate' character of inter-organizational ties facilitates the emergence of different, segmented epistemic communities in which most members align themselves on local opinion leaders. Actors use different identity criteria to seek advice at that level. Contrary to what happens at the intra-organizational level, homophily effects at the inter-organizational level create a polarized exchange system along the 'science vs economics' divide. In this context, such a strong relational investment by elite members could stem from an attempt to compensate for the negative effects of polarization. Finally, statistical analysis of the substructures characterizing the advice networks confirms this trend. We observe an over-representation of transitive sub-structures in addition to the abovementioned homophilous effects.

In summary, we have shown that the choice of cognitive authorities and appropriate bodies of knowledge at the inter-organizational level tends to take place in a polarized environment where different epistemic communities coexist. In this uncertain context, negotiations for coorientation of activities and learning weaken the position of opinion leaders who must share their status by investing heavily in relationships in order to find support for their knowledge claims and appropriateness judgments. We suggest that, in contexts in which hierarchy is weak and horizontal peer relations strong, these characteristics of the advice network at the inter-organizational level show the extent to which learning depends on the symbolic dimension of social exchanges, such as institutional affiliation, shared background or epistemic status.

The phenomenon of social polarization that we examined prevents the creation of a common frame of reference facilitating the exchanges in the collective. In that respect, the coexistence of several epistemic communities may be associated with the risk of inefficiencies in learning and a subsequent lack of coordination. In this context, it would make sense to look at institutional mechanisms that would help in creating consensus on appropriate bodies of knowledge and legitimate rules of exchange in that social milieu. Future explorations should focus on the identification of mechanisms that are likely to counter the effect of polarization and segmentation. This work will benefit from new models testing for 
mulitplex effects, which will explore the polarization process based on the simultaneous analysis of the different advice networks that can explain in part the homophilous effect that we observe.

From a managerial perspective, these results show how difficult it is for entrepreneurs to access different networks of informal exchange that coexist within an industrial milieu. The symbolic terrain, outside of which it is impossible for a scientist to create a company with its own project, can also create obstacles when trying to get access to resources controlled by other epistemic communities. In a polarized context where the choice of an epistemic authority is not consensual, entrepreneurs who are able or allowed to integrate within several communities increase their chances of success. With respect to deriving policy implications from that statement, much remains to be done, in France as in many other countries.

\section{Acknowledgments}

We thank the entrepreneurs who were patient and kind enough to answer our questions. We also thank France Biotech, a non profit trade association, Angelita de Francisco, its former Director, for their support, as well as the reviewers and editors of EJIM for their help.

\section{References}

Argote, Linda, Aimee Kane and John Levine (2005) “'Knowledge transfer between groups via personnel rotation: Effects of social identity and knowledge quality'. Organizational Behavior and Human Decisions Processes, 96: 56-71.

Argyris, Chris and Donald Schön (1978) Organizational learning: Theory, Method, and Practice. Reading, Mass: Addison Wesley.

Aharonson, B., Baum, J., Plunket, A. (2008) 'Inventive and uninventive clusters: The case of Canadian biotechnology', Research Policy, Vol. 37, pp.1108-1131.

Arora, A., and Gambardella, A. (1990) 'Complementarity and external linkages: the strategies of the large firms in biotechnology', The journal of industrial economics, Vol. 38, pp.361379. 
Audretsch, D. and Stephan, P. (1996) 'Company-Scientist Locational Links: The Case of Biotechnology', The American Economic Review, pp.641-652.

Autant-Bernard, C., Mangematin, V. and Massard, N. (2006) 'Creation of Biotech in France', Small Business Economics, Vol. 26, pp.173-87.

Barley, Stephen R. (1990) "The alignment of technology and structure through roles and networks"'. Administrative Science Quarterly, 35: 61-103.

Baum, J., Calabrese, T. and Silverman, B. (2000) 'Don't go it alone: Allieance network composition and startups' performance in Canadian biotechnology', Strategic Management Journal, Vol. 21, pp.267-94.

Blau, P.M. (1955) The dynamics of bureaucracy, Chicago: University of Chicago Press.

Blau, P. M. (1964) Exchange and power in social life, New York: John Wiley.

Boufaden, N. and Plunket, A. (2005) 'Investigating technological and geographic proximity on forms' innovation in an immature cluster: the Paris area biotech cluster', DRUID Conference, Copenhagen.

Borgatti, Stephen P. and Rob Cross (2003) "A Relational view of information seeking and learning in social networks'". Management Science, 49: 432-445.

Casper, S. (2007) 'How do technology clusters emerge and become sustainable? Social network formation and inter-firm mobility within the San Diego biotechnology cluster', Research Policy, Vol. 36, pp.438-455.

Cross, Rob, Borgatti, Stephen P., Parker, Andrew (2001), "Beyond answers: dimensions of the advice network", Social Networks, 23: 215-235

Gertler, M.S. and Levitte, Y. M. (2005) 'Local Nodes in Global Networks: The Geography of Knowledge Flows in Biotechnology Innovation', Industry and Innovation, Vol. 12, pp.487507.

Gibbons, D. (2004) 'Friendship and Advice Networks in the Context of Changing Professional Values', Administrative Science Quarterly, Vol. 49, pp.238-262.

Gilding, M. (2008) “The tyranny of distance': Biotechnology networks and Clusters in the antipodes', Research Policy, Vol. 37, pp.1132-1144.

Hansen, M.T. (2002) «Knowledge networks : explaining effective knowledge sharing in multi-unit companies », Organisation Science, 13:232-248 
Ibarra, Herminia and Steven B. Andrews (1993) “Power, social influence and sense making: Effects of network centrality and proximity on employee perceptions"'. Administrative Science Quarterly, 38: 277-303.

Kilduff, Martin and Tsai, W. (2003) Social networks and organizations. Thousand Oaks, CA: Sage

Kogut, B. (2000) 'The Network as Knowledge: Generative Rules and the Emergence of Structure', Strategic Management Journal, Vol. 21, pp.405-425.

Kogut, B. and Udo Zander (1996) 'What firms do: Coordination, identity, and learning”. Organization Science, 7: 502-518.

Krackhardt, D. (1987) "Cognitive Social Structures", Social Networks, 9 :109-134.

Krackhardt, D. (1990) "Assessing the Political Landscape: Structure, Cognition, and Power in Organizations", Administrative Science Quarterly, 35:342-369.

Lazega, E. (1992) Micropolitics ok Knowledge: Communication and indirect control in workgroups, Aldine-de-Gruyter, New York.

Lazega, E. (2001), The Collegial Phenomenon : The Social mechanisms of cooperation among peers in a corporate law partnership, Oxford, Oxford University Press.

Lazega, E. and Van Duijn, M. (1997) 'Position in formal structure, personal characteristics and choices of advisors in a law firm: A logistic regression model for dyadic network data', Social Networks, Vol. 19, pp.375-397.

Lazega, E. and Mounier, L. (2002) 'Interdependent entrepreneurs and the social discipline of their cooperation: The research program of structural economic sociology for a society of organizations', in Favereau, O. and Lazega, E. (eds), Conventions and Structures in Economic Organization, Edward Elgar Publishing, pp.147-199.

Lazega, E., Mounier, L., Jourda, M.-T. and Stofer, R. (2006a) 'Organizational vs. personal social capital in scientists' performance: A multi-level network study of elite French cancer researchers (1996-1998)', Scientometrics, Vol. 67, No. 1, pp. 27-44.

Lazega, L., Lemercier, C. and Mounier, L. (2006b) 'A Spinning top model of formal organization and informal behavior: dynamics of advice networks among judges in a commercial court', European Management Review, Vol. 0, pp.1-10. 
Lemarié, S., Mangematin, V. and Torre, A. (2001) 'Is the creation and development of biotech localized? Conclusion drawn from the French case', Small Business Economics, Vol. 17, pp.61-76.

Levitt, Barbara and James G. March (1988) “'Organizational learning”. Annual Review of Sociology, 14: 319-340.

Mangematin, V., Lemarie, S., Boissin, J.P., Catherine, D., Corolleur F., Corolini, R. and Trommetter, M. (2003) 'Development of SMEs and heterogeneity of trajectories: the case of biotechnology in France', Research Policy, Vol. 32, pp.621-638.

March, James G. and Herbert A. Simon (1958) Organizations. New York: Wiley.

Mcdonald, M. and Westphal, J. (2003) 'Getting by with the Advice of Their Friends: CEOs' Advice Networks and Firms' Strategic Responses to Poor Performance', Administrative Science Quarterly, Vol. 48, pp. 1-32.

Mizruchi, Mark S. and Linda B. Stearns (2001), "Gettings Deals Done: The Use of Social Networks in Bank Decision Making”, American Sociological Review, 66: 647-741.

Niosi, J. (2003) 'Alliances are not enough explaining rapid growth in biotechnology firms', Research Policy, Vol. 32, pp.737-750.

Pina-Stranger, A. (forthcoming, 2009) «Transfert technologique et processus collectif d'apprentissage dans l'industrie des biotechnologies en France », Revue Sociologie Santé, $\mathrm{n}^{\circ} 30$.

Pisano, G. (1991) 'The governance of innovation: vertical integration and collaborative arrangements in the biotechnology industry', Research Policy, Vol. 20, pp. 237-249.

Powell, W.W., Koput, K. and Smith-Doerr, L. (1996) 'Inter-Organizational Collaboration and the locus of innovation: networks of learning in the biotechnology', Administrative Science Quarterly, Vol. 41, pp.116-45.

Powell, W.W., Koput, K., Smith-Doerr, L. and Owen-Smith, J. (1999) 'Network position and firm performance: Organizational returns to collaboration in the biotechnology industry', Research in the Sociology of Organizations, Vol. 16, pp.129-159.

Powell, W.W., Koput, K., Bowie, J. and Smith-Doerr, L. (2002) 'The Spatial Clustering of Science and Capital: accounting for Biotech Firm-Venture Capital relationships', Regional Studies, Vol. 36, pp.291-305. 
Reynaud, J.-D. (1989) Les règles du jeu, Paris, Armand Colin.

Robins, G., Snijders, T., Wang, P., Handcock, M., Pattison, P. (2007) 'Recent developments in exponential random graph $\left(p^{*}\right)$ models for social networks', Social Networks, Vol. 29, pp.192-215.

Robins, G. and Pattison, P. (2005) 'Interdependencies and Social Processes: Generalized Dependence Structures.' in Models and Methods in Social Network Analysis, edited by Peter Carrington, P. Scott, J. and Wasserman, S., Cambridge, England: Cambridge University Press, pp.192-214

Rulke, Diane L. and Josephz Galaskiewicz (2000) "Distribution of knowledge, group network structure, and group performance'”. Management Science, 46(5): 612-625.

Salman, N. and Saives, A.-L. (2005) 'Indirect networks: an intangible resource for biotechnology innovation', $R \& D$ Management, Vol. 35, pp.203-215.

Senker, J. and Sharp, M. (1997) 'Organizational learning in cooperative alliances: Some case studies in Biotechnology', Technology Analysis \& Strategic Management, Vol. 9, pp.35-51.

Škerlavaj, Miha and Dimovski, Vlado (2006) 'Social network approach to organizational learning', Journal of Applied Business Research, 22: 89-97.

Snijders, T., Pattison, P., Robins, G.L. and Handcock, M., (2006) 'Newspecifications for exponential random graph models', Sociological Methodology, Vol. 36, No. 1, pp. 99-153.

Snijders, T., Steglich, C., Schweinberger, M. and Huisman, M. (2007) 'Manual for Siena version 3.11', Groningen, University of Groningen, ICS, Oxford, University of Oxford, Department of Statistics [http://stat.gamma.rug.nl/stocnet].

Sparrowe, R., Liden, R., Wayne, S. and Kraimer, M. (2001) 'Social networks and the performance of individuals and groups', Academy of Management Journal, Vol. 44, No 2, pp. $316-325$.

Stuart, T. and Sorenson, O. (2003) 'The geography of opportunity: spatial heterogeneity in founding rates and the performance of biotechnology firms', Research Policy, Vol. 32, pp.229-253.

Stuart, T., Ozdemir, S. and Ding, W. (2007) 'Vertical alliance networks: The case of university-biotechnology-pharmaceutical alliance chains', Research Policy, Vol. 36, pp.477498. 
Tsaï, W. (2002) «Social structure of coopetition within a multiunit organization: coordination, competition, and intraoraganisational knowledge sharing", Organisation Science, 13: 179-190

Van Duijn, M., Snijders, T. and Zijlstra, B. (2004) 'p2: a random effects model with covariates for directed graphs', Statistica Neerlandica, Vol. 58, pp.234-254.

Waters, M. (1989) 'Collegiality, Bureaucratization, and Professionalization: A Weberian Analysis', American Journal of Sociology, Vol. 94, No. 5, pp. 945.

Weick, Karl (1979) 'Cognitive processes in organizations”. Research in Organizational Behavior, 1: 41-74.

Zijlstra, B. and Van Duijn, M. (2008) 'Manual p2, version 4.0.0.0', edition 6, August 21, Groningen, University of Groningen [http://stat.gamma.rug.nl/stocnet].

\footnotetext{
${ }^{1}$ Usually collegiality does not mean congeniality (Waters, 1998).

${ }^{2}$ The two kinds of models are part of the StOCNET environment: http://stat.gamma.rug.nl/stocnet.
} 
Figure 1 - Independent variables

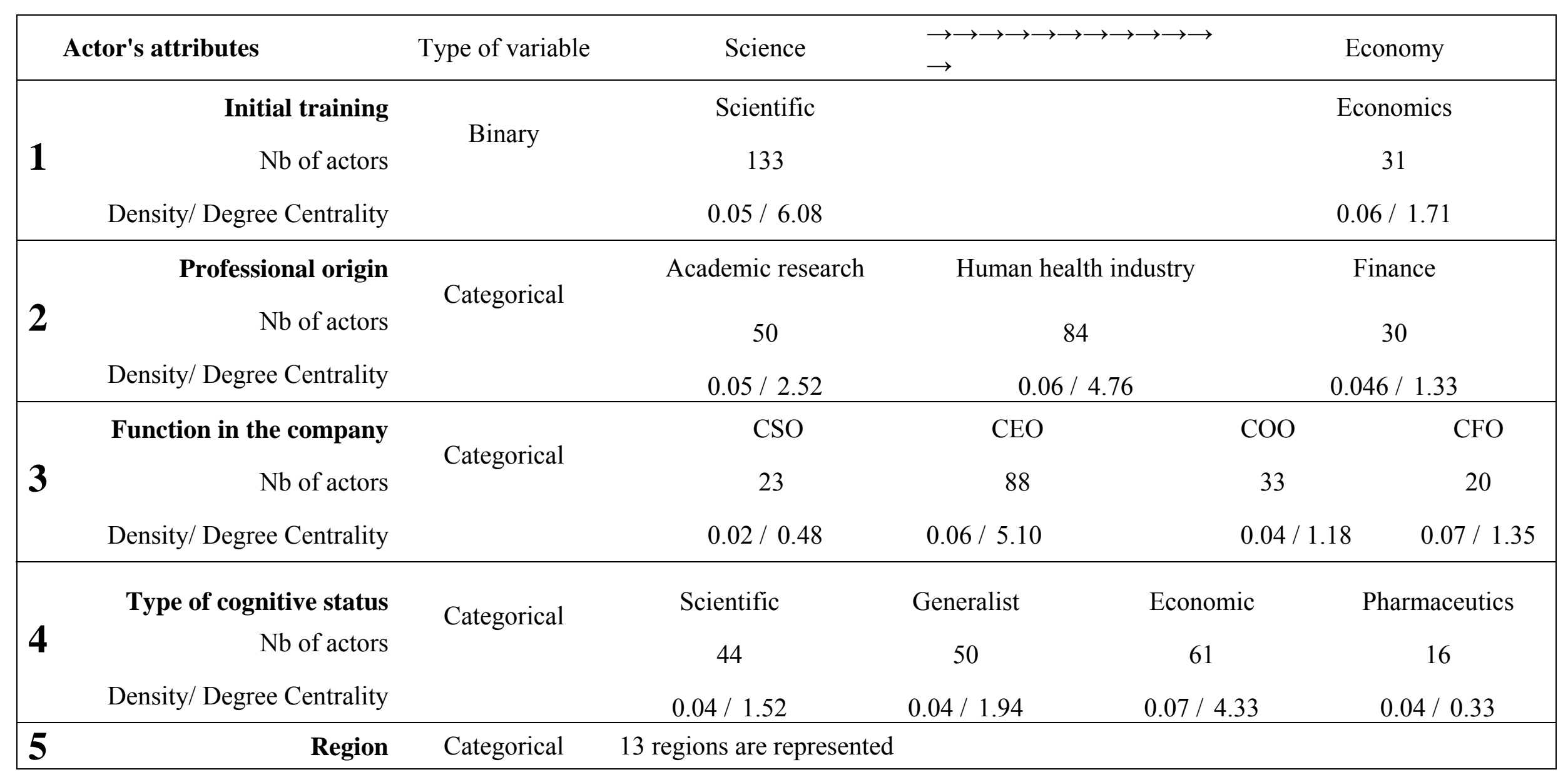


FIGURE 2. - Positive correlation between indegree and outdegree centralities in the advice network at the inter-organizational level

0.54 correlation (with opinion leaders)

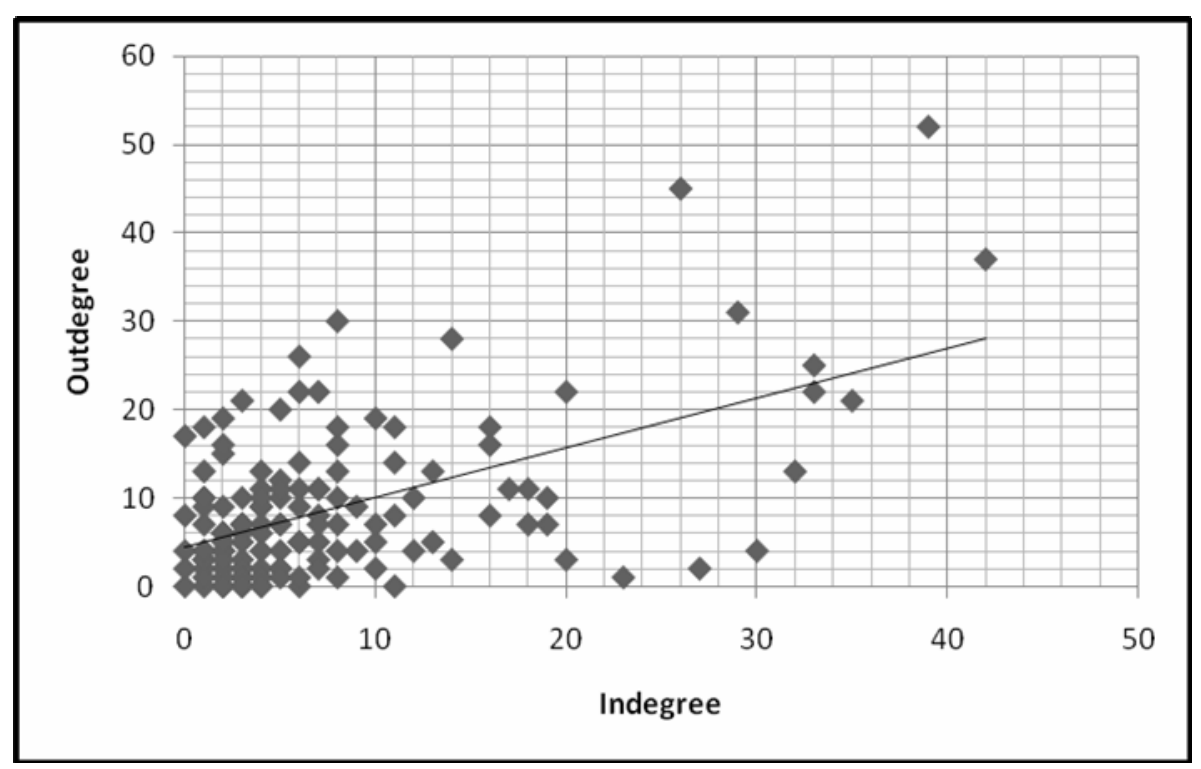

0.27 correlation (without opinion leaders)

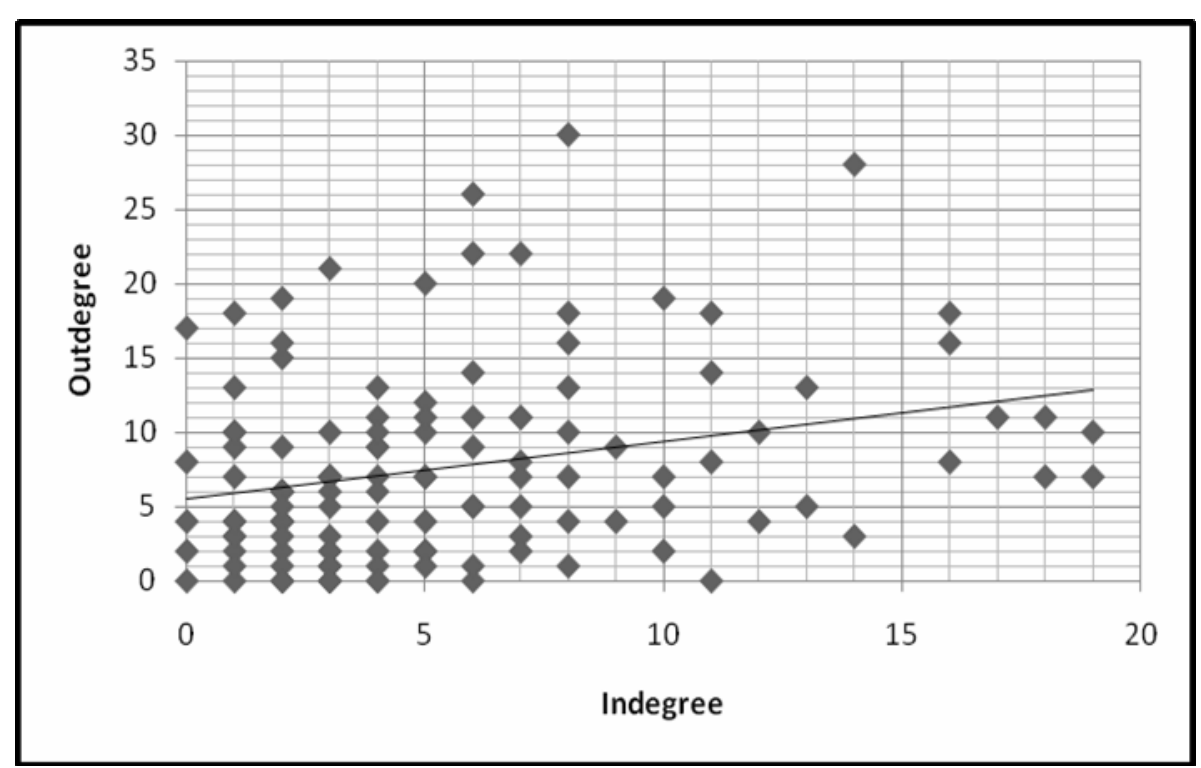

Legend: Indegree centrality counts the number of choices received and outdgeree centrality the number of choices made by the 138 entrepreneurs who responded to the sociometric questionnaire. The 13 opinion leaders taken out of the right hand figure represent $10 \%$ of the actors. 
Figure $3-p 2$ parameters for the effect of dissimilarities on the selection of advisors.

\begin{tabular}{|c|c|c|c|c|c|}
\hline & Model 1 & Model 2 & Model 3 & Model 4 & Model 5 \\
\hline Independent variables & Empty model & $\begin{array}{l}\text { Differences in } \\
\text { function in the } \\
\text { company }\end{array}$ & $\begin{array}{c}\text { Differences in } \\
\text { professional origin }\end{array}$ & $\begin{array}{l}\text { Differences in } \\
\text { epistemic status }\end{array}$ & $\begin{array}{c}\text { Transversal } \\
\text { differences } \\
\text { "Science/Economics" }\end{array}$ \\
\hline \multicolumn{6}{|l|}{ Random effects } \\
\hline Sender variance & $1.18(0.20)$ & $1.22(0.21)$ & $1.21(0.20)$ & $1.23(0.21)$ & $1.23(0.21)$ \\
\hline Receiver variance & $1.09(0.17)$ & $1.10(0.17)$ & $1.08(0.17)$ & $1.13(0.18)$ & $1.07(0.17)$ \\
\hline $\begin{array}{l}\text { Sender receiver covariance } \\
\text { Overall effects }\end{array}$ & $0.02(0.12)$ & $0.01(0.13)$ & $-0.02(0.13)$ & $0.02(0.13)$ & $-0.01(0.13)$ \\
\hline Density & $-4.06(0.35)$ & $-3.91(0.14)$ & $-3.78(0.14)$ & $-2.62(0.26)$ & $-3.89(0.13)$ \\
\hline Reciprocity & $2.14(0.61)$ & $2.23(0.18)$ & $2.40(0.19)$ & $1.30(0.91)$ & $2.58(0.15)$ \\
\hline \multicolumn{6}{|l|}{ Specific density effects } \\
\hline \multicolumn{6}{|l|}{ Differences in function in the company } \\
\hline CEO-CFO & & $-0.58(0.15)$ & & & \\
\hline CEO-CSO & & $-0.22(0.19)$ & & & \\
\hline CEO-COO & & $-0.06(0.11)$ & & & \\
\hline CFO-CSO & & $-1.59(0.46)$ & & & $-0.97(0.46)$ \\
\hline $\mathrm{CFO}-\mathrm{COO}$ & & $-0.81(0.29)$ & & & \\
\hline CSO-COO & & $-0.50(0.30)$ & & & \\
\hline \multicolumn{6}{|l|}{ Differences in professional origin } \\
\hline Financial and Academic & & & $-0.82(0.17)$ & & $-0.35(0.17)$ \\
\hline Financial and Health industry & & & $-0.51(0.13)$ & & \\
\hline Academic and Health industry & & & $-0.43(0.10)$ & & \\
\hline \multicolumn{6}{|l|}{ Differences in epistemic status } \\
\hline Economic and Scientific. & & & & $-0.56(0.13)$ & $-0.48(0.12)$ \\
\hline Economic and. Generalist & & & & $-0.24(0.12)$ & \\
\hline Scientific and Generalist & & & & $0.06(0.15)$ & \\
\hline Deviance & 5828.81 & 5791.37 & 5787.52 & 5782.22 & 5783.50 \\
\hline
\end{tabular}


Legend: Coefficients presented in this table are $p 2$ parameters for the effect of dissimilarities on the selection of advisors. Standard errors are in parentheses. Parameters at least twice as large as their standard errors are considered significant. Dyadic independent variables correspond to attribute dissimilarities linked to the functional division of work in the firm (Model 1), to the professional origin (Model 2), and to the type of cognitive status (Model 3) of actors. Deviance decreases from Model 1 to Model 4, indicating that parameters tested in Model 4 show a better fit to the observed network. For reasons of space, specific reciprocity effects are not included in the table but they were systematically included in the analyses. 
Figure 4 - Exponential random graph models (ERGM) parameters for the effect of similarities on the selection of advisors

\begin{tabular}{|c|c|c|}
\hline Independent variables & Model 1 & Model 2 \\
\hline Structural effects & & \\
\hline Observed Density & 0.0429 & 0.0429 \\
\hline Reciprocity & $1.41(0.12)$ & $1.39(0.12)$ \\
\hline 3-cycles & $-0.12(0.04)$ & $-0.12(0.04)$ \\
\hline Alternating out- $k$-stars & $0.76(0.09)$ & $0.47(0.12)$ \\
\hline Alternating $k$-triangles & $0.95(0.05)$ & $0.97(0.05)$ \\
\hline $\begin{array}{r}\text { Alternating independent } \\
\text { towpaths }\end{array}$ & $-0.05(0.00)$ & $-0.05(0.01)$ \\
\hline \multicolumn{3}{|l|}{ Exogenous effects } \\
\hline Same initial training & $0.04(0.03)$ & $0.06(0.03)$ \\
\hline Same professional origin & $0.11(0.03)$ & $0.12(0.03)$ \\
\hline Same function in the company & $0.07(0.03)$ & $0.08(0.03)$ \\
\hline Same Region & $0.08(0.02)$ & $0.08(0.03)$ \\
\hline \multicolumn{3}{|l|}{ Endogenous effects } \\
\hline Same cognitive status & $0.15(0.04)$ & $0.17(0.04)$ \\
\hline $\begin{array}{r}\text { Dummy variable for missing } \\
\text { outdegree ego }\end{array}$ & & $-6.91(8.66)$ \\
\hline
\end{tabular}

Legend: Standard errors are in parentheses. Parameters at least twice as large as their standard errors are considered significant. 